Urban Water Systems \& Floods III 23

\title{
INTEGRATED STRATEGIES FOR RIVER RESTORATION AND LAND RE-NATURALIZATION IN URBAN AREAS: A CASE STUDY IN MILAN, ITALY
}

\author{
FRANCO RAIMONDI ${ }^{1,2}$, CLAUDIA DRESTI ${ }^{3}$, MARIANA MARCHIONI $^{1}$, \\ DARIO KIAN $^{2}$, STEFANO MAMBRETTI ${ }^{1,4}$ \& GIANFRANCO BECCIU ${ }^{1}$ \\ ${ }^{1}$ Politecnico di Milano, Italy \\ ${ }^{2}$ Ersaf, Italy \\ ${ }^{3}$ National Research Council, Water Research Institute, Italy \\ ${ }^{4}$ Wessex Institute of Technology, UK
}

\begin{abstract}
Densely populated areas are frequently affected by floods, risking people's safety and economic activities. In Milan, Italy, the Seveso river crosses the urban area mainly in close conduits frequently flooding. The sprawling of urban areas combined with the intensification of extreme storm events increase the frequency of floods requiring pursuing a new approach on urban water management. The solutions must be sought not only on structural facilities directly on the river with large-scale dimensions: they present expensive construction and operation costs, and only give an apparent sense of security in a short period. It is necessary to identify natural-based strategies for the fluvial territory management taking a comprehensive view on watershed scale, moving from a traditional local and monothematic approach to a global and multisectoral towards water sensitive cities. This research aim is to assess some effects arising from the applications of river restoration and sustainable urban drainage techniques on a stretch of the Seveso river within Parco Nord, in particular through measures of parking de-waterproofing, improvement of river natural expansion and morphology re-naturalization and diversification of riverbanks and riverbed. To assess the effects, a 2D flow simulation using Hec-Ras and the recalculation of the river functionality index have been conducted. The results show benefits not only in raising better water and environmental quality, thanks to the enhancing of river functionality level, but also in risk mitigation, with the reduction of floodable areas, above all significatively for the storm event with a return period lower than 10 years. This research confirms the validity of the new approach and constitutes the first step towards the creation of a practical guide tool for the watershed management with similar characteristics to that of the Seveso river, to reach the European Directives' requests and to build up a strategy for adapting to climate change.
\end{abstract}

Keywords: river restoration, spatial planning, river contract, sustainable drainage, environmental quality enhancement, risk mitigation.

\section{INTRODUCTION}

Most of oldest cities have arisen on the water as it is a source of sustenance, a driving force and an important communication route. Over the centuries, the pursuit of progress has led to the exploitation of natural resources and the transformation of river basins, profoundly changing their characteristics over time. Floodplain occupation for new developments and the use to collect and conduct wastewater and stormwater has relegated rivers and streams to a marginal role, shifting from a resource to a liability. Watercourses pollutions pose a public health risk and floods cause people and economical loss. Traditional structural solutions not always have the expected effect, in some cases can increase the problem, specially downstream. In light of the continuous urban and climatic changes, it is necessary to start new processes for a better management of the territory which combined with the study and application of new so-called green and blue infrastructures [1] for the management of rainwater, such as those offered by sustainable drainage techniques (SUDS). They constitute the starting point for preserving people's quality of life and economic activities, by returning 
to conditions of the river basins that are as natural as possible and restoring the populationriver link by rediscovering the potential and opportunities it offers [2], [3]. Due to its historically known characteristics and criticalities, the Seveso watershed lends itself well to be the subject of experimentation with these new strategies.

\section{BACKGROUND}

Seveso river's course extends (Fig. 1) for about $50 \mathrm{~km}$ from Como Lake to the city of Milan, which it crosses completely below the surface, starting from Ornato Street up to the beginning of the Redefossi channel on the southern border of the city, and then flowing into the Lambro river in the municipality of Melegnano. Its territory, especially the metropolitan area north of Milan, has been the scene, since the 1960s, of an intense urban development that has transformed it into one of the most economically developed but also most densely populated areas of Europe. In fact, although it represents only $2.5 \%$ (about $617 \mathrm{~km}^{2}$, of which $53 \%$ is occupied by anthropic activities) of the total area of Lombardy, the watershed collects a population of approximately $2,300,000$ inhabitants (more than $1 / 5$ of the total) with a density of $3,730 \mathrm{ab} / \mathrm{km}^{2}$. The metropolitan city expansion has increasingly reduced the river space and has led to the loss of its natural connotations, the deterioration of the water quality and the ecosystem and the increase in the flood risk.

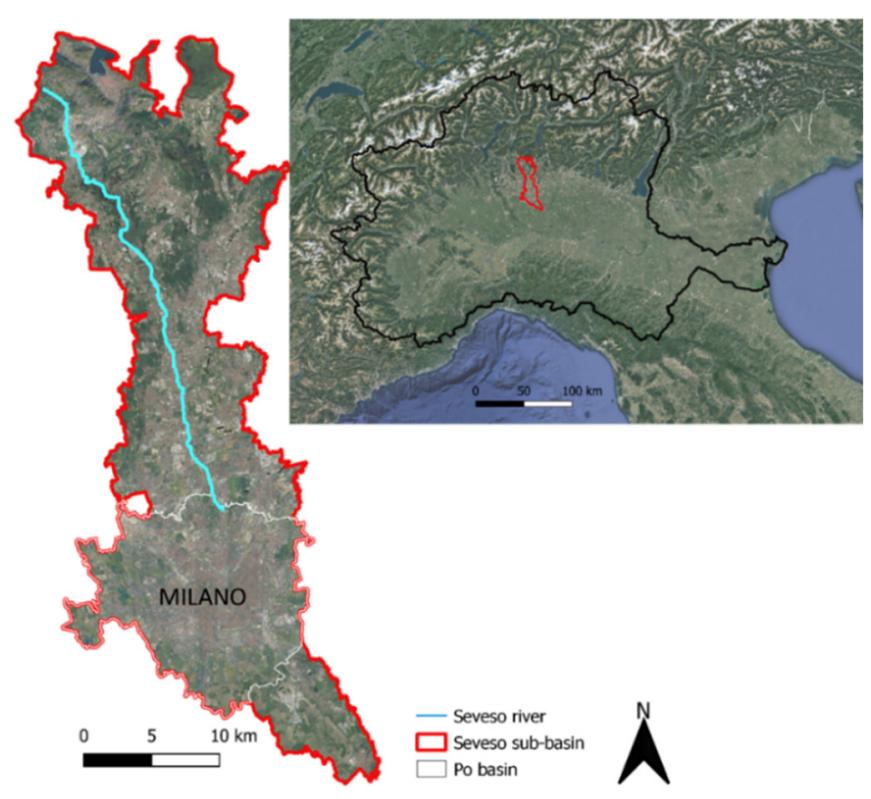

Figure 1: Seveso sub-basin location.

In particular, soil sealing has drastically reduced the percentage of rainwater infiltration and the concentration time by increasing the surface runoff. To reduce the risk of flooding, we have relied on channelization, artificialisation of the riverbed and the riverbanks and flood detention basins [4]. These solutions have not always led to satisfactory results and have often only moved the problem downstream and contributed to worsening of the water quality and the river ecosystem. It has been estimated that 104 floods have occurred in Milan since 1976 (2.6 floods each year), eight of which between 2010 and 2014. In the same way, 
to solve the problem of the water quality worsening, we mainly intervened on the collection network effectiveness and in an attempt to improve the yields of the treatment plants. However, the level of quality remains low as evidenced by the various quality indices (ecological, morphological and functional) which in the stretch north of Milan present the worst values such as to require an extension for the achievement of the "good" quality status imposed by the Water Directive since 2015 to 2027. It is glaring that exclusively sectoral solutions for local and structural emergency resolution are not sufficient to solve problems and sometimes present technical and economic impossibilities to achieve good results. Moreover, in the last years the rainfall regimes have changed as well as the waterproofing of the soil has increased. New solutions are necessary.

\section{NEW APPROACH}

The awareness of changing the paradigm in spatial planning has led the Lombardy Region to become the promoter of a new territorial management tool, the River Contract [5], a negotiated, voluntary and participatory planning process to which all stakeholders of a river basin can adhere. The Contract reproduces the objectives of the European Directives (mainly the Water Directive 2000/60/EC [6] and the Flood Directive 2007/60/EC [7]) and of the sector plans which implement and in turn integrate the provisions, respectively the Piano di Tutela ed Uso delle Acque (PTUA, Protection and Use Plan of the Waters) [8] and the Piano di Gestione del Rischio Alluvioni (PGRA, Flood Risk Management Plan) [9]. The limit of large area planning as well as urban and individual planning is to tackle sectoral issues and limit oneself to simple imposition or simple respect of constraints, without deeply investigating the reality of the territories. The River Contract has the specific aim of integrating and making applicable in the territory what is reported in the Directives and Plans, however taking into account the needs of the latter and planning from a watershed perspective based on the environmental characteristics. Doing so it is possible to exceed the logic administrative boundaries and to avoid the implementation of single-issue interventions, aimed exclusively at solving the site-specific problem, without evaluating the repercussions on the various environmental components and in other areas of the watershed. For this reason, within the Seveso River Contract, signed in 2006, the Strategic Sub-Basin Project has developed since 2014 and approved in December 2017, a co-planning process with local actors that leads to the development of shared project proposals aimed at mitigating the hydraulic risk and enhancing watershed quality and ecological set-up based on the interests of the stakeholders and an in-depth knowledge of the critical issues, needs and potential of the area [5].

\section{CASE STUDY}

A project idea of the redevelopment of the river environment in the north of Milan, more precisely of a stretch of about $2 \mathrm{~km}$ of the Seveso river within the Parco Nord, between the municipalities of Milan, Cormano and Bresso, was born. The idea, included in the action plan of the Strategic Sub-Basin Project contains a series of specific interventions aimed primarily at recovering the ecological role of the river but which simultaneously contribute to the mitigation of the hydraulic risk and the improvement of the water quality. The area presents itself as one of the most critical of the basin as regards the flood risk, due to the percentage of waterproofed surface (more than doubled from the 1950s-1960s and with values currently higher than $70 \%$ of the municipal areas involved) and the fact that it is located in the closing section of the watershed just upstream of the manhole in Ornato street in Milan, which allows the transit of an estimated flow of not more than $30-40 \mathrm{~m}^{3} / \mathrm{s}$, just sufficient for the drainage of rainwater urban areas for events that do not exceed a return time of 2 years. The risk is 
significantly increased by the high number of people exposed since the municipalities concerned, despite excluding Milan, have a population density of approximately 5,980 inhabitants $/ \mathrm{km}^{2}$. Water quality is also a critical issue since here the lowest values of the entire river rod are recorded for all quality indices. The interventions that have been purposed concerned both the river rod and the surrounding territory, as shown in Fig. 2.

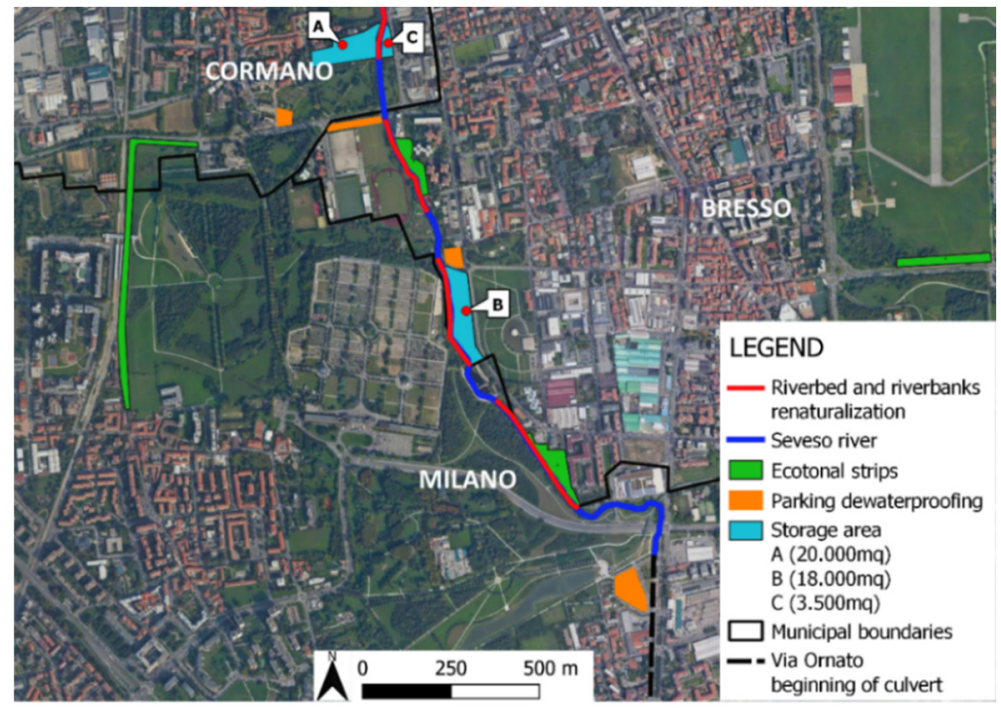

Figure 2: Proposed interventions map.

The construction of four ecotonal buffers is expected, of which two adjoining the water course for a total length of 430 meters and two others along the roads bordering the park for a total length of $1,100 \mathrm{~m}$. The strips must have a width of not less than $10 \mathrm{~m}$ and be composed of rows of arboreal (willow, alder, poplar, oak and hornbeam) and shrubby (elderberry, privet, viburnum, hawthorn and blackthorn) species alternating. The total area covered by the ecotonal strips has been calculated in $24,000 \mathrm{~m}^{2}$.

For the banks, consolidation and re-naturalization measures are envisaged. In particular, in two points the placement of cyclopean boulders at the foot of the bank surmounted by a bundle of chestnut wood with planting of shrub species suitable for the riparian environment (willow, tamarisk, privet and dogwood) or grassed through the hydroseeding technique in the case of steep slopes is expected. In a very steep stretch of about $90 \mathrm{~m}$ long and due to the lack of space, the introduction of gabions is expected.

In the riverbed, in correspondence with the sections of the bank in question, the aim is the positioning of triangular boulders deflectors and the creation of scrapers for the morphological diversification of the riverbed in addition to the insertion of macrophytes.

The three storage areas are to be created as follows. For area A $\left(20,000 \mathrm{~m}^{2}\right.$ (Fig. 2)), in the municipality of Cormano, on the hydrographic right, which is currently fenced and abandoned, the wall that divides it from Seveso for a stretch of about $80 \mathrm{~m}$ is expected to be demolished and the replacement with fascinate alive in the first half, lower to facilitate natural expansion during floods, and of cyclopean boulders in the second half at the outer part of the loop where the hydrodynamic stresses are greater. Area $\mathrm{C}\left(3,500 \mathrm{~m}^{2}\right.$ (Fig. 2)) is located on the opposite side of the river in front of the first to replace an ecological platform. The 
construction method is identical to the previous one, after de-waterproofing, but without the use of cyclopean boulders. Area B (18,000 $\mathrm{m}^{2}$ (Fig. 2)), in the municipality of Bresso, involves a public park to which the area of another ecological platform (Fig. 2) to be waterproofed. In this case the side is lowered and the foot protected by a concrete wall replaced with cyclopean and bundled boulders. In all three areas, lowering of the countryside level up to $1 \mathrm{~m}$ above the riverbed, the planting of indigenous shrub species and the delimitation with a grassy embankment for the protection of the external areas is expected.

The latest proposal concerns the de-waterproofing of four parking areas, that cover a total area of $13,000 \mathrm{~m}^{2}$, using permeable pavements.

\section{MATERIALS AND METHODS}

For the evaluation of the effects of the hypothesized interventions, all the necessary data were collected. As regards the quality of the water, the tables were acquired which, section by section, led to the evaluation of the river functionality index (IFF) [10]. The index, developed by the Istituto Superiore per la Protezione e la Ricerca Ambientale (ISPRA (Upper Institute for Environmental and Protection Research)) [10], evaluates the functionality of the river ecosystem intended as the integration of structural, morphological and biotic factors concerning not only strictly the river but also the surrounding area. The evaluation form consists of 14 questions (including vegetation, morphology, riverbed composition, etc.) to which answers are assigned numerical values proportionally increasing with functionality. The sum of the scores obtained for each question determines the final judgment of the ecological functionality (Table 1). For Seveso, the data available date back to the beginning of 2017 and have been processed by Fondazione Lombardia per l'Ambiente (FLA (Lombardy Foundation for the Environment)) [11]. The Seveso course is characterized by decreasing values proceeding from the source to Milan. The average value corresponds to the judgement "poor", while in the case study area the average value is 55 (poor-very bad) with a maximum of 103 (middling-poor).

Table 1: IFF index values, levels and judgements.

\begin{tabular}{|c|c|l|}
\hline IFF value & $\begin{array}{c}\text { Functionality } \\
\text { level }\end{array}$ & Functionality judgement \\
\hline $261-300$ & I & Excellent \\
\hline $251-260$ & I-II & Excellent-good \\
\hline $201-250$ & II & Good \\
\hline $181-200$ & II-III & Good-middling \\
\hline $121-180$ & III & Middling \\
\hline $101-120$ & III-IV & Middling-poor \\
\hline $61-100$ & IV & Poor \\
\hline $51-60$ & IV-V & Poor-very bad \\
\hline $14-50$ & V & Very bad \\
\hline
\end{tabular}

As regards the data necessary for the hydraulic calculations, the geometric characteristics of the sections along the entire course of the Seveso obtained from the District Authority of the Po River basin (AdbPo) [12] were found, and available in shapefile and excel format from the Geoportal of Lombardy region [13]. The Digital Terrain Model (DTM) of the Lombardy region, with a $20 \times 20$ resolution, the shapefile relating to the intended use of the soils was obtained from the Geoportal too. From the AdbPo website [12], Annex 3 to the technical report of the project plan for the variant of the Piano di Assetto Idrogeologico (PAI 
(Hydrogeological Conformation Plan)) of the Seveso stream, regarding the updating of hydrological and hydraulic analyzes, has been downloaded. In particular, the flood hydrograms upstream of the Canale Scolmatore di Nord-Ovest (CSNO (North West Filling Channel)) outlet were considered for events with return period of 10, 100 and 500 years at present. Finally, through the Agenzia Regionale per la Protezione Ambientale (ARPA (Regional Environmental Protection Agency)) [14] it has been possible to obtain the continuously measured flow rates at the hydrometric station in the municipality of Paderno Dugnano in the period 19 June 2014-5 November 2019.

The ecological impact of the action is evaluated through the analysis of the variation of the IFF index. The work consists in redefining the values to be attributed to the 14 questions in the form and the recalculation of the overall judgment for all the sections subject to intervention.

To evaluated the floodable areas instead the Hec-Ras software with mixed 1D/2D simulation was used. The geometric pattern (river and sections) was obtained by tracing the shapefiles downloaded from the geoportal in Hec-Ras which are therefore georeferenced. The Digital Terrain Model, the information layer on land cover and the satellite image were then added. The definition of Manning's roughness coefficients for each section and land use was carried out following the criteria and tables reported in the literature [15], [16].

In order to represents the beginning of the underground channel in Ornato Street, which constitutes the downstream boundary condition as the maximum flow rate is $35 \mathrm{~m}^{3} / \mathrm{s}$, at the end of the open-air section of Seveso a culvert with an opening of $4 \times 2 \mathrm{~m}$ has been inserted.

With the help of the satellite image, the outlines of the three storage areas and areas considered floodable have been defined using as boundaries the presence of road and railway embankments and including the districts that have notoriously and frequently affected by floods. Two floodable areas have been designed, one on the hydrographic left and one on the hydrographic right and south of the Ornato Street culvert. The separation between the storage areas and those considered floodable has been identified with a structure that follows the course of the ground according to the DTM by increasing the height by $1 \mathrm{~m}$.

For the creation of the computational mesh, a value of $20 \mathrm{~m}$ per side has been set for each cell. In the presence of the three storage areas, the riverbank presents a lowering at the height of the water tie for the closest section corresponding to the flow rate which determines the achievement of the maximum drainage capacity of the culvert. In order to facilitate the complete emptying of the areas at the end of the flood event, to restore the reservoir capacity for the next event, a gate has been inserted for each area. The gate opens when the water level in the area is higher than that in the nearest section.

For each return period (10, 100 and 500 years) two simulations were carried out, one that represents the current state and one that considers the creation of the three storage areas and their simultaneous operation. As input data, the hydrograms processed by AdbPo for each return period upstream of the CSNO have been entered, decreased at each time step by $30 \mathrm{~m}^{3} / \mathrm{s}$ in the event of optimal operation of the CSNO itself in periods of flood. To these simulations are added those relating to four periods of variable length extracted from the measurements of the continuous flow rates from ARPA, also recalculated considering the flow derived by the CSNO. The periods considered coincide with particularly important events that caused flooding and damage in the northern part of the city of Milan. Specifically, the following periods were taken into consideration: 23 June-14 July 2014 and 3-27 November 2014, in which the maximum flow reached values comparable to those of events with a return period of 100 years, 31 July- 8 August 2016 characterized by two peaks 5 days apart and 19 June-7 July 2018 with a maximum flow rate of $63 \mathrm{~m}^{3} / \mathrm{s}$. Also in these cases, two simulations were carried out for each event, one in its current state and which reproduces 
the floods recorded in some areas of Milan and one in the scenario of complete realization and simultaneous operation of the three storage areas.

\section{RESULTS AND DISCUSSION}

From the simulations carried out using hydrograms with the return period of 10, 100 and 500 years, it emerges that the areas involved in flooding in the post operam scenario are always less than the current ones, as shown in Table 2 and as an example in Figs 3 and 4. In all three cases the flood moment is delayed by about half an hour and the time in which the most affected areas remain flooded tends to decrease. As for the height of the water in the flooded areas, this is a bit lower $(5 \mathrm{~cm})$ in the post operam scenario in the area on the left hydrographic, while in the remaining areas there is a substantial parity. As regards the velocity in the flooded areas, this is lower of about $0.2 \mathrm{~m} / \mathrm{s}$ for the future scenarios than the present ones; the same difference is observed between the highest velocity within the riverbed, which is reached in the straight stretch downstream of the last storage area. Turning to the events actually recorded, the decrease in flooded areas is much more evident, especially in the events of June-July 2018 and July-August 2016 (Figs 5 and 6) which have the lowest maximum flow rates. In both cases, the lower speed of the current that comes out of the riverbed in future scenarios causes the water to expand very slowly. For the events of JuneJuly 2014 (Figs 7 and 8) and the month of November 2014, having recorded flow rates comparable to those with return times of 100 years, the positive effects due to the reservoirs are less evident. The water level in the flooded areas is in general $3-5 \mathrm{~cm}$ lower only for 2016 and 2018 events with storage areas, while in the 2014 events is very similar. The maximum speed reached by the current is $0.2-0.3 \mathrm{~m} / \mathrm{s}$ lower and the beginning of the flooding with the implementation of the interventions is delayed 30 minutes, except for November 2014. Interesting are the episodes of July-August 2016 and November 2014 in which there are two close-range peaks. In 2016, the first peak (about $48 \mathrm{~m}^{3} / \mathrm{s}$ ) appears to be completely absorbed by the reservoir system while in 2014 this does not occur and this is due to the exceptional nature of the period which has flow rates almost constantly above $35 \mathrm{~m}^{3} / \mathrm{s}$ with peaks of 73 and $120 \mathrm{~m}^{3} / \mathrm{s}$ within 3 days, a sign that the system tends to be ineffective when the maximum conveying capacity of the culvert is equalled or exceeded, albeit slightly, for a few days consecutively.

Table 2: Expansion of flooded areas.

\begin{tabular}{|l|l|c|c|c|}
\hline & & \multicolumn{3}{|c|}{ Floodable areas $\left(\mathrm{km}^{2}\right)$} \\
\hline Event & Time & $\begin{array}{c}\text { Current } \\
\text { state }\end{array}$ & $\begin{array}{c}\text { Storage } \\
\text { area }\end{array}$ & Gap \\
\hline 10 years return period & 5 hours after the beginning & 5.1 & 4.3 & 0.8 \\
\hline 100 years return period & 5 hours after the beginning & 6.3 & 5.5 & 0.8 \\
\hline 500 years return period & 5 hours after the beginning & 8.4 & 6.2 & 2.2 \\
\hline 23 June-14 July 2014 & 8 July 2014, 05:30 & 6.3 & 5.4 & 0.9 \\
\hline 3-27 November 2014 & 15 November 2014, 20:30 & 8.5 & 8 & 0.5 \\
\hline 31 July-8 August 2016 & 7 August 2016,00:00 & 3.2 & 1.3 & 1.9 \\
\hline 19 June-7 July 2018 & 5 July 2018, 08:00 & 2.4 & 1.1 & 1.3 \\
\hline
\end{tabular}




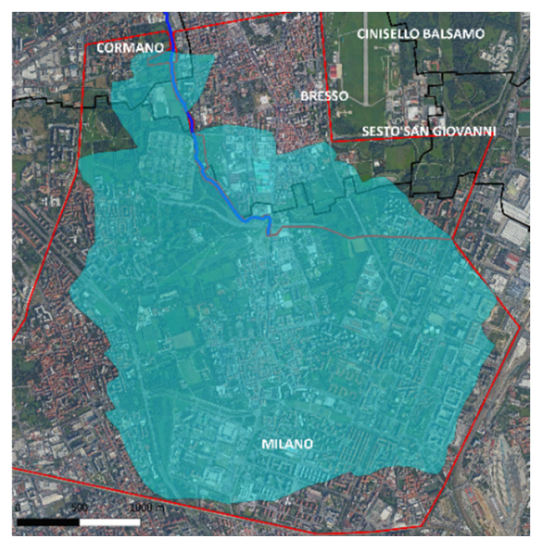

Figure 3: Flooded areas during 500 years return period event at the current state.

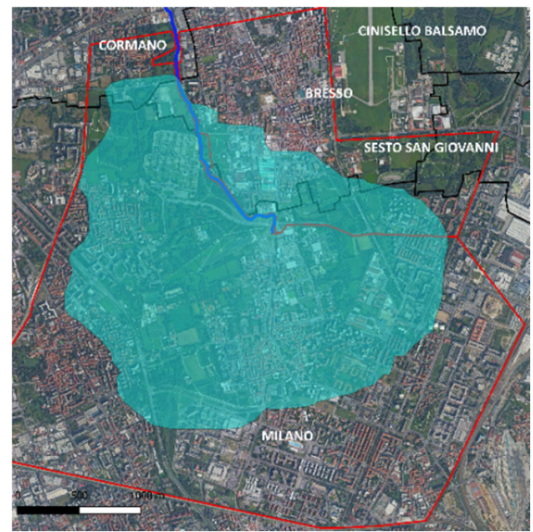

Figure 4: Flooded areas during 500 years return period with storage areas.

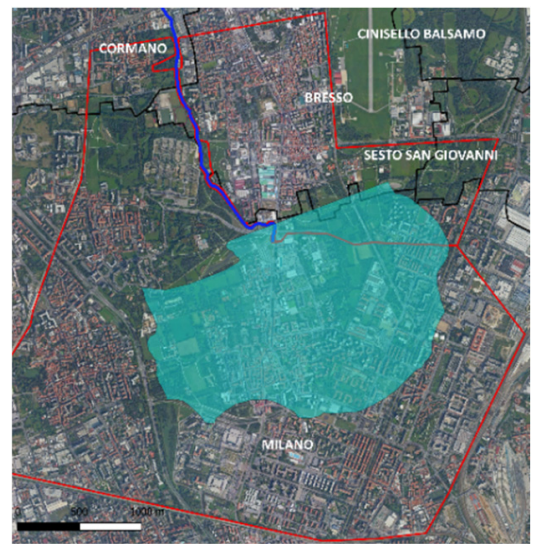

Figure 5: Flooded areas on 7 August 2016 (00:00). 


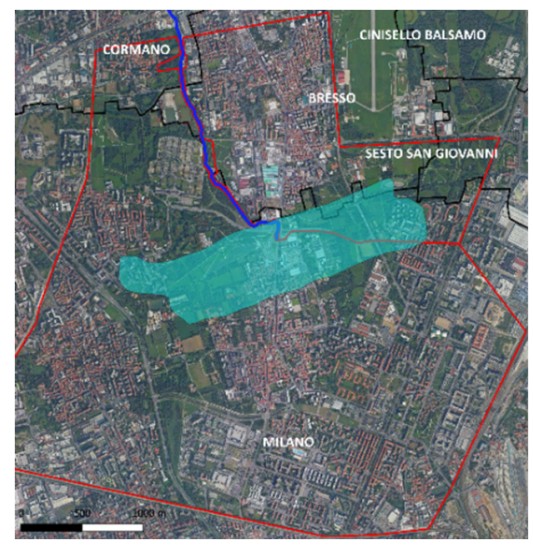

Figure 6: Flooded areas on 7 August 2016 (00:00) with storage areas.

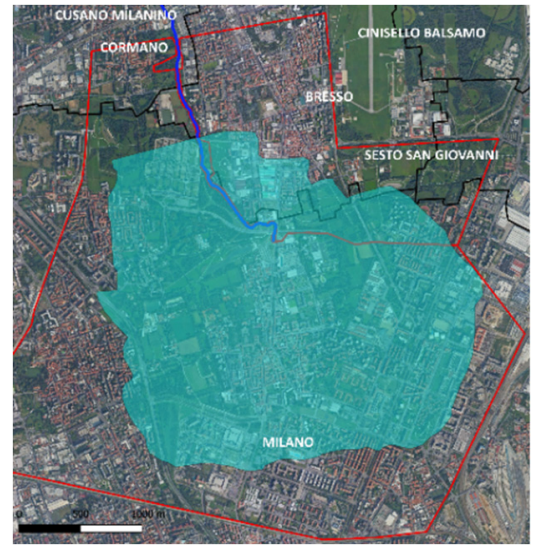

Figure 7: Flooded areas on 8 July 2014 (05:30).

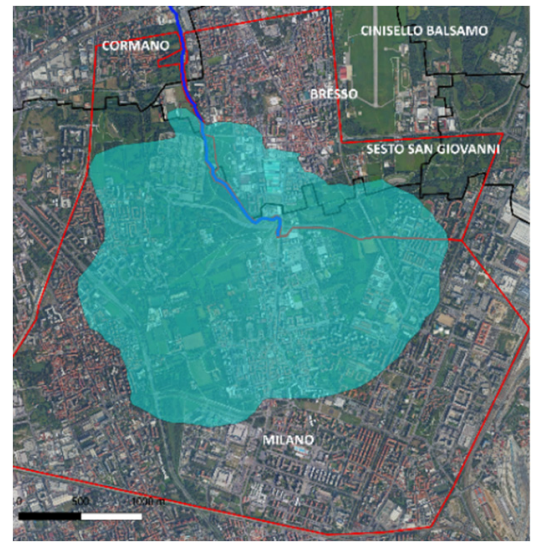

Figure 8: Flooded areas on 8 July 2014 (05:30) with storage areas. 
For the ecological aspect, the evaluation of the hypothesized interventions is entrusted to the recalculation of the river functionality index. Based on the location of the renaturalization and morphological diversification of the riverbed and riverbanks, five files have been reviewed, three concerning the hydrographic right and two, the left. Everywhere, the implementation of the project proposals determines the transition to the next level of functionality of the IFF, with an increasing of value between 32 and 63 points. In particular, the improvements enhance the functionality judgement from poor to middling in three cases and from poor-very bad to middling-poor and from very bad to poor in the other two. Among the various questions that make-up the index, those that benefit most from the proposed actions and that determine the improvement of functionality are the quality, continuity and width of the vegetation in the primary and secondary peripheral areas, the conformation of the riverbed, the stabilization of the riverbanks and in some cases the enlargement and renaturalization of the cross sections. It is very difficult to be able to reach better judgments due to the serious state of neglect facing the river at this time and the lack of physical space to allow to operate more consistently.

In addition to the tangible results of the IFF and the hydraulic simulations, there are a whole series of positive effects directly and indirectly linked to the proposed interventions that are not easily quantifiable or in any case not in the short term and which concern both the improvement of water quality and ecological functionality of the river and the decrease in hydraulic risk. From a water quality point of view, some interventions, although not acting directly for this purpose, are still able to lighten the polluting load linked to the washout of the cemented surfaces and increase the self-cleaning capacity of the river. To the first purpose contributes the de-waterproofing of the car parks; several studies [17], [18] demonstrate how the coating of parking surfaces with techniques that facilitate the infiltration of rainwater determines a reduction of the polluting load especially related to suspended solids and in some cases also to some heavy metals [19] being trapped in the pervious asphalt without soil contamination. Moreover, it is well known that pervious pavements have the capability to delay runoff reducing peak discharge [20], [21]. The increase in self-purifying capacity is guaranteed instead from the morphological diversification of the riverbed such as the insertion of scrapers, boulders and brushes which increase the turbulence locally and contribute to lowering the water temperature and improving oxygenation, aspects useful for removing of excess nutrients. Placement of boulders has a positive effect in improving coarse particulate organic matter retention too [22]. In addition, these solutions, if well designed, allow the current to be conveyed to the center of the riverbed during lean periods, avoiding the formation of stagnant pools and therefore of poorly hygienic conditions. It has been demonstrated that the diversification of the riverbed allows the formation of fundamental microhabitats [23] for the restoration of macroinvertebrates, that perform several functions in river ecosystem [24], and for a future return of fishes. Moreover, the presence of macrophyte species enhance photosynthetic productivity [25] and creates favorable conditions for the development of communities of microorganisms that through various types of chemical-physical processes are able to purify the course of pollutants as well as contribute to the sediment retention [26].

In general, the erosive problem of undermining the foot of the riverbanks is instead solved by the naturalistic engineering and morphological diversification interventions for which the probability of trees falling in the riverbed is considerably reduced.

Finally, the ecotonal strips on the roads allow a pre-treatment of rainwater while beyond the riverbanks they contribute to stabilize them and offer refuge and sustenance for the numerous species of birds and small mammals that live in the park, partially giving back to the river the role of ecological rod which belongs to him. 


\section{CONCLUSIONS}

The proposal is a good example of a search for shared and integrated solutions to critical issues in the river sector and is evidence of the awareness of the need to make a change in the approach to spatial planning and in the effectiveness of the co-planning process with the local actors identified by the Lombardy Region in the Sub-basin Strategic Project. From an ecological point of view the actions proposed are able to enhance river environment and consequently water quality also if at a local scale. Regarding risk mitigation the system seems to be able to significantly reduce the floodable areas for events with return period lower than 10 years, while the benefits during extreme events are limited. This proposal is the starting point towards the restoration of a situation that is as close as possible to naturalness. However, in this strongly anthropized context, it is necessary not to remain focused only on the river auction and the surrounding areas, but to assess the possibility of intervention throughout the watershed. In this sense, it is necessary to carry out an overall evaluation of the entire hydrological balance, also in light of the hydraulic invariance regulation [27], and to promote flexible and sustainable solutions for the accumulation, treatment [28] and reuse of rainwater by promoting infiltration in the soil and increasing the concentration time to obtain sensitive results on a watershed scale from all points of view (ecological, water quality and risk mitigation) and as a strategy for adapting to climate change. Finally, the decision support offered by the scientific models that confirm the effectiveness of the process and help progress towards the change of approach to planning that is required cannot be ignored.

\section{REFERENCES}

[1] Lawson, E. et al., Delivering and evaluating the multiple flood risk benefits in bluegreen cities: An interdisciplinary approach. WIT Transactions on Ecology and the Environment, vol. 184, WIT Press: Southampton and Boston, pp. 113-124, 2014.

[2] Owens-Viani, L., Restoring urban streams offers social, environmental and economic benefits. Sustainable Use of Water. California Success Stories, Pacific Institute: Oakland, California, pp. 283-304, 1999.

[3] Everard, M. \& Moggridge, H.L., Rediscovering the value of urban rivers. Urban Ecosystems, 15(2), pp. 293-314, 2012. https://doi.org/ 10.1007/s11252-011-0174-7.

[4] Becciu, G., Ghia, M. \& Mambretti, S., A century of works on River Seveso: From unregulated development to basin reclamation. International Journal of Environmental Impacts, 1(4), pp. 461-472, 2018. https://doi.org/10.2495/EI-V1-N4-461-472.

[5] Regione Lombardia, ERSAF, Progetto Strategico di Sottobacino del torrente Seveso, 2017. (In Italian.) www.contrattidifiume.it.

[6] European Union, Directive 2000/60/CE of the European Parliament and of the Council Establishing a Framework for the Community Action in the Field of Water Policy.

[7] European Union, Directive 2007/60/CE of the European Parliament and of the Council on the Assessment and Management of Flood Risk.

[8] Regione Lombardia, Unità Organizzativa Risorse Idriche e Programmazione Ambientale, Piano di Tutela e Uso delle Acque, 2016. (In Italian.) www.regione.lombardia.it.

[9] Autorità di bacino distrettuale del fiume Po, Piano di Gestione del Rischio Alluvioni, 2015. (In Italian.) www.adbpo.gov.it.

[10] ISPRA, IFF 2007-indice di funzionalità fluviale, 2007. (In Italian.) Www.isprambiente.gov.it.

[11] Fondazione Lombardia per l'Ambiente, www.flanet.org. 
[12] Autorità di bacino distrettuale del fiume Po, Allegato 3 alla relazione tecnica del progetto di variante al pai del torrente Seveso, 2017. (In Italian.) www.adbpo.gov.it.

[13] Geoportale Regione Lombardia, www.geoportale.regione.lombardia.it/download-dati.

[14] Agenzia Regionale per la Protezione Ambientale, www.arpalombardia.it.

[15] Chow, V.T., Open Channel Hydraulics, McGraw-Hill: New York, pp. 101-125, 1994.

[16] Cowan W.L., Estimating hydraulic roughness coefficients. Agricultural Engineering, 37(7), 1956.

[17] Marchioni, M.L. \& Becciu, G., Permeable pavement used on sustainable drainage systems (SUDs): a synthetic review of recent literature. WIT Transactions on The Built Environment, vol. 139, WIT Press: Southampton and Boston, p. 12, 2014. http://dx.doi.org/10.2495/uw140161.

[18] Pratt, C.J., Permeable pavements for stormwater quality enhancement. Urban Stormwater Quality Enhancement: Source Control, Retrofitting, and Combined Sewer Technology, ASCE, 1990.

[19] Legret, M. \& Colandini, V., Effects of a porous pavement with reservoir structure on runoff water: Water quality and fate of heavy metals. Water Science and Technology, 39(2), pp. 111-117, 1999. http://dx.doi.org/10.1016/s0273-1223(99)00014-1.

[20] Marchioni M. \& Becciu G., Experimental results on permeable pavements in urban areas: A synthetic review. International Journal of Sustainable Development and Planning, 10(6), pp. 806-817, 2015.

[21] Pratt, C.J., Mantle, J. \& Schofield, P., UK research into the performance of permeable pavement, reservoir structures in controlling stormwater discharge quantity and quality. Water Science and Technology, 32(1), pp. 63-69, 1995. https://doi.org/10.1016/0273-1223(95)00539-y.

[22] Lepori, F., Palm, D. \& Malmqvist, B., Effects of stream restoration on ecosystem functioning: Detritus retentiveness and decomposition. Journal of Applied Ecology, 42, pp. 228-238, 2005. https://doi.org/10.1111/j.1365-2664.2004.00965.x.

[23] Groll, M., Relations between the microscale riverbed morphology and the macrozoobenthos: Implications for the ecological quality assessment and the definition of reference conditions. International Journal of Environmental Impacts, 1(3), pp. 375-389, 2018. https://doi.org/10.2495/EI-V1-N3-375-389.

[24] Wallace, J.B. \& Webster, J.R., The role of macroinvertebrates in stream ecosystem function. Annual Review of Entomology, 41, pp. 115-139, 1996. https://doi.org/10.1146/annurev.en.41.010196.000555.

[25] Jarvie, H.P., Love, A.J., Williams, R.J. \& Neal, C., Measuring in-stream productivity: The potential of continuous chlorophyll and dissolved oxygen monitoring for assessing the ecological status of surface waters. Water Science and Technology, 48(10), pp. 191-198, 2003.

[26] Schmid, B.H., Innocenti, I. \& Sanfilippo, U., Characterizing solute transport with transient storage across a range of experiments in Austrian and Italian streams. Advances in Water Resources, 33, pp. 1340-1346, 2010.

[27] Regione Lombardia, Regolamento recante criteri e metodi per il rispetto del principio dell'invarianza idraulica ed idrologica, 2017. (In Italian.) www.regione.lombardia.it.

[28] Becciu, G. \& Raimondi, A., Probabilistic analysis of the retention time in stormwater detention facilities. Procedia Engineering, 119, pp. 1299-1307, 2015. 